\title{
O USO DA VÍRGULA NA ESCRITA DE TEXTOS ACADÊMICOS
}

\section{THE USE OF THE COMMA IN THE WRITING OF ACADEMIC TEXTS}

\author{
Agda Negrão Moreira Chahim* \\ Deborah Dayse Silva Gomes Ribeiro*
}

\begin{abstract}
RESUMO: O presente artigo tem por objetivo descrever o emprego da vírgula e sua relação com os componentes sintáticos e semânticos da Língua Portuguesa na escrita de textos acadêmicos do curso de Geografia produzidos no ano de 2020 pela Universidade Federal do Triângulo Mineiro (UFTM). A pesquisa bibliográfica realizada se baseia nos principais teóricos e suas abordagens relacionadas ao uso da vírgula, as diferenças e/ou as aproximações nas abordagens e nos conceitos. Simultaneamente ocorre a análise textual dos alunos do curso de Geografia e a maneira que a vírgula é utilizada em suas escritas. O uso da vírgula é associado como parte fulcral para o bom desenvolvimento do texto e para o bom entendimento do leitor. Como conclusão nota-se que o sujeito tende a usar a vírgula com base na respiração, utilizando a mesma sem levar em consideração os termos sintáticos e semânticos da Língua Portuguesa, ou seja, uma maneira errônea de utilizar a mesma, tendo em vista que o sujeito não foi ensinado para essa finalidade, com isso, saber e compreender como usar a pontuação.
\end{abstract}

Palavras-chave: Pontuação; Vírgula; Língua Portuguesa; Escrita no Ensino Superior.

ABSTRACT: This article aims to describe the usage of the comma and its relation to syntactic and semantic components in Portuguese throught the writing of academic texts from the Geography course produced in 2020 by the Universidade Federal do Triangulo Mineiro (UFTM). The bibliographical research was based on the main Portuguese grammar theorists and their approaches to how comma can be used, considering the differences and/or similarities in their visions and concepts. Simultaneously, a textual analysis of Geography course students was made to demonstrate how comma is used in their writing. The use of comma is considered a key part of good writing development and the reader's good understanding of the text. It was noted that the Subject tends to use comma based on its breathing, not applying the syntactic and semantic terms of the Portuguese grammar rules, using it

\footnotetext{
* Mestranda em Educação pela Universidade Federal do Triângulo Mineiro (UFTM). Contato: agda.nmoreira@gmail.com

${ }^{*}$ Mestranda em Educação pela Universidade Federal do Triângulo Mineiro (UFTM). Professora da Educação Básica em Uberaba (MG). Contato: deborahdaysesilva@gmail.com
} 
in an erroneous way, demonstrating how they do not know how to apply what was taught, that is, knowing and understanding how to use the punctuation rules.

Keywords: Punctuation; Comma; Portuguese language; Written in Higher Education.

\section{INTRODUÇÃO}

Estar diante da necessidade de escrever implica estar diante de medos e incertezas inerentes à escrita de um texto. Desse modo, atualiza-se para o sujeito o traçado da entrada na linguagem feito por qualquer falante. A depender do encaminhamento dado aos medos, ao refazer esse traçado, alguns passam a procurar um modelo que acomode o texto e as posições nele constituídas para se livrar do embate com os próprios temores. (BARZOTTO, 2016, p.13). No entanto, no percurso da produção escrita, além do embate inerente ao medo, percebe-se o medo quanto à pontuação, ou seja, quando pontuar e quais os critérios.

Sabe-se que o uso da vírgula possui papel fulcral diante das funções sintáticas e semânticas e, para o bom desenvolvimento de um texto, faz-se necessário romper com a ideia ainda arraigada que o seu uso advém somente de uma "pausa" na escrita de modo que a leitura possa fluir. Saber empregar a vírgula adequadamente vai além de produzir um texto coerente e coeso, mas, sobretudo, demonstrar a proficiência de seus usuários. Sob essa perspectiva, a pontuação apresenta uma estreita relação com o conteúdo e sentido da mensagem, considerando o significado de uma frase a fim de evitar a ambiguidade em um texto, uma vez que, na produção escrita, se perde o recurso sonoro da língua oral e a vírgula tenta exprimir alguns desses nuances da oralidade.

Sintaticamente, ou seja, em relação às classes gramaticais, a vírgula ocupa lugar de destaque nessas estruturas, coordenando termos de igual valor sintático, separando elementos de uma oração cuja relação não seja direta com os demais, como os vocativos e, inclusive, para supressão, como ocorre com os verbos. Sendo assim, o objetivo do presente artigo configura-se em analisar o 
porquê a vírgula é elidida enquanto unidade sintática da oração e no interior dos períodos de produções acadêmicas, uma vez que a produção escrita ocorre mediante aos sinais de pontuação para imprimir no texto as pausas, entonações, coesão e coerência, as quais, sem a vírgula não seria possível expressá-la de modo significativo ao leitor de seu texto.

Embora as regras estabelecidas nas gramáticas não sejam gerais para conceituá-las com um único consenso, o presente artigo propõe-se a verificar mediante à pesquisa bibliográfica quais os contextos em que a vírgula deve ser aplicada ou evitada e até que ponto resulta na dificuldade da produção escrita.

\section{PERCURSO TEÓRICO}

De acordo com Geraldi (2003), a questão da linguagem é fundamental no desenvolvimento de todo e qualquer homem; ela é o elemento constitutivo e organizador do processo de apreensão de conceitos que permitem aos sujeitos compreenderem o mundo e nele agir. Assim, para o autor, a prática de produção textual tornou-se algo indispensável para o ensino e aprendizagem da língua, uma vez que é no texto que a língua "se revela em sua totalidade quer enquanto conjunto de forma, quer enquanto discurso" (GERALDI, 1993, p.135). A necessidade de comunicação do sujeito para com a produção escrita atrela diretamente aos recursos de escrita, assim como os sinais e símbolos carregados de significado para emitir ao interlocutor uma mensagem.

No presente estudo, aborda-se a linguagem sob o aspecto da língua, a qual, para Rocha Lima (2008, p. 5) "é um sistema; um conjunto organizado e opositivo de relações, adotado por determinada sociedade para permitir 0 exercício da linguagem entre os homens". Para Abaurre (2010, p.17), a "linguagem é uma atividade humana e é sempre utilizada em situação de interlocução", quer seja mediante as expressões artísticas, musicais, gestuais e qualquer outra manifestação cuja pretensão seja a interação. Rocha Lima (2008, p.4), por sua vez, retrata sobre dois tipos de expressão linguística, sendo a fala e a escrita. Na produção escrita a sonoridade da fala passa a ser expressa mentalmente por meio de símbolos gráficos, ou seja, se configura senão como 
um imperfeito suplente da fala, pressupondo além da significação dos enunciados, o timbre da voz, a entoação, aspectos subsidiáveis do gesto e da expressividade. Além disso, a escrita necessita da pontuação para lograr êxito no processo de comunicação, no qual, de acordo com Bechara (2009) a pontuação é um:

sistema de reforço da escrita, constituído de sinais sintáticos, destinados a organizar as relações e a proporção das partes do discurso e das pausas orais e escritas. Estes sinais também participam de todas as funções da sintaxe, gramaticais, entonacionais e semânticas (BECHARA, 2009, p. 604).

Nesse sentido, verifica-se que a pontuação registra na escrita determinados elementos da oralidade, tais como o ritmo, pausas, entonações das linhas melódicas de modo a indicar uma pergunta, afirmação ou exortação. Todos esses aspectos manifestam-se naturalmente no momento de fala, mas, na prática da escrita, faz-se necessário utilizar, sobretudo saber utilizar os sinais de pontuação afim de garantir ao leitor a compreensão, ou seja, a interpretação coesa e coerente de sua escrita, de modo a acrescentá-lo significações e informações e não cair no abismo de uma escrita incompreensível dado ao fato do não uso das pontuações, sobretudo à vírgula.

Embora não haja um consenso quanto as definições sobre o uso da pontuação, alguns autores abordam sobre suas funcionalidades. Para Mesquita (1996, p. 461), os sinais de pontuação se configuram nos recursos gráficos que imprimem ao texto escrito as características da língua falada. Para o autor, existem dois grupos, sendo os sinais que indicam pausa, como o ponto e vírgula, o ponto e a vírgula e os sinais que indicam entonação, assim como os dois pontos, o ponto de exclamação e interrogação, as reticências, as aspas, os parênteses, os colchetes e o travessão. Tal classificação que dividem os sinais que marcam pausa e entonação também é abordada por Cunha (2001, p.643), no entanto, o autor aborda que fazer a mera distinção entre os sinais de pontuação é algo cômodo didaticamente. Em consonância com a concepção dos sinais de pontuação, Rocha Lima (2008) não se fundamenta nas questões de pausa e entonação, mas sim em uma classificação quanto às pausas rítmicas, 
sendo as que não interrompem o discurso e a pausa que indica a finalização do discurso.

\section{APONTAMENTOS SOBRE O USO DA VÍRGULA}

Após tais conceitualizações no que tange a pontuação e sua importância, faz-se necessário abordar sobre a vírgula, no qual Segundo Cunha (2001), Terra (1996) e Mesquita (1996), compreende-se que a vírgula concerne em uma pequena e breve pausa, no entanto, Luft (1996) rebate tal assertiva, uma vez que para o autor a pontuação resulta na obediência de critérios sintáticos e não prosódicos, ou seja, o momento de pontuar não está atrelado ao seguimento rítmico ou qualquer outra propriedade acústica da fala, mas sim nas relações sintáticas dos elementos constituintes da oração. Nesse sentido, utilizar a vírgula como ligação entre a pausa melódica da fala configura-se no modo errôneo de seu uso, uma vez que sua função é indicar a falta ou quebra de ligação sintática no interior dos enunciados.

Segundo Sautchuk (2010, p. 153):

O emprego da vírgula, em português, é realizado em função da sintaxe de construção das frases e da colocação dos termos essenciais, integrantes e acessórios das orações, e não por motivos "sonoros". Somente as pausas sintático semânticas têm correspondência no sistema escrito do português: as pausas respiratórias não têm. Em nossa língua, a ordem não marcada melodicamente é o SVC e, por isso, esses elementos sintáticos não podem ser separados por vírgula. Baseando se nesse princípio, somente quando um elemento "estranho" (termo acessório) é colocado entre esse padrão ou antes dele, essa colocação é ou deve ser marcada melodicamente por meio de vírgula.

Desse modo, a autora aborda que a utilização da vírgula ocorre em detrimento da colocação dos termos integrantes e acessórios de forma sistematizada. Ou seja, não se tem o uso da vírgula como marcação melódica, no entanto, utiliza-se a vírgula para romper a ordem direta ou introdução de algum termo acessório no interior da estrutura ou anterior a ela. 
Mesquita (1996), por sua vez, atrela o uso da vírgula em relação à gramática da língua, elidindo também o aspecto melódico. Para a autora, a produção escrita é que gerencia o seu emprego, pois ora, se trata de uma escrita na qual em determinado momento dirijo-me a um "outro" pela ordem direta, gramaticalmente trata-se de um vocativo, cujo uso da vírgula é fundamental para a separação entre os termos da oração, assim ocorre para a utilização do aposto, os adjuntos adverbiais que aparecem no início ou no meio das orações; para indicar a elipse, separar os termos de uma enumeração etc. Por outro lado, entre as orações, o uso da vírgula é essencial para que haja a separação entre as orações independentes, ou seja, nas orações coordenadas assindéticas e nas orações subordinadas adjetivas explicativas e orações subordinadas adverbiais, sobretudo quando são antecedentes as orações principais.

Para Cegala (2008), o emprego da vírgula consiste em separar as orações e os elementos dessas orações, de modo a separar orações justapostas, orações intercaladas e explicativas, predicativos, expressões retificadas, para separar adjuntos adverbiais e determinadas conjunções propositivas, para separar o que se deseja ressaltar, ou seja, percebe-se que o uso da vírgula se configura no uso gramatical da língua. $O$ autor ainda ressalta três situações nas quais não se emprega a vírgula, embora ainda seja encontrado nas produções escritas, tal como a vírgula para separar o sujeito e o verbo, os verbos e os complementos verbais, e antes das orações adverbiais consecutivas.

Segundo Hauy (2014), a vírgula é um sinal gráfico de pontuação cuja função está na indicação de pausa e empregada na reestruturação sintática dos períodos de modo a dar clareza ao discurso. Segundo a autora, no período simples, a vírgula é utilizada para três finalidades: para separar; para indicar e para sinalizar algo no interior da oração. Em relação ao período composto, a mesma autora aborda que a vírgula é utilizada para separar as orações coordenadas assindéticas e sindéticas, no entanto, ressalta que não se utiliza vírgula se a conjunção coordenativa aditiva estiver na posição antecedente $e$, caso o sujeito seja o mesmo em ambas as orações.

Martins (2010) assevera que, de certo modo, a vírgula é uma pausa de pequena durabilidade, no entanto, ressalta que as pausas com base na 
respiração não funcionam de recurso para o seu emprego, assim como a vírgula também não denota todas as pausas respiratórias da fala. De forma categórica, após conceituar a vírgula, a autora afirma que o uso da vírgula é vedado entre o sujeito e o predicado e entre o verbo e seus complementos.

\section{DESDOBRAMENTOS E ELUCIDAÇÕES ACERCA DA VÍRGULA}

De acordo com o objetivo da presente pesquisa, cujo intuito fora descrever o emprego da vírgula e sua relação com os componentes sintáticos e semânticos da Língua Portuguesa, faz-se necessário retomar os principais teóricos, de modo a apontar as diferenças ou aproximações nas abordagens e nos conceitos.

Como fora abordado anteriormente, nota-se que, com base em Mesquita (1996) e Cunha (2001), têm-se os sinais de pontuação divididos entre os que indicam pausa e os que indicam a melodia ou entonação manifestantes na escrita. Rocha Lima (2008) aborda essa diferença se restringindo apenas a conceituar a pontuação como um demarcador de pausas rítmicas, no entanto, o que Cunha e Mesquita chamam de melodia, Rocha Lima afirma tratar de outro tipo de pausa, na qual destaca uma intenção ou estado emotivo, sendo classificado por Bechara como sinais de comunicação (mensagem).

Considerando os sinais que indicam pausa, Rocha Lima os separa entre os que não inibem o discurso e os que indicam o fim do discurso ou de parte dele. Em consonância, Bechara (2009) ao classificar os sinais de pontuação aborda que existem os sinais separadores e os sinais de comunicação ou mensagem que ainda podem ser subdivididos entre os que apresentam uma pausa conclusa ou uma pausa inconclusa. Cegala (2008), ao asseverar que os autores não possuem um consenso sobre o uso da pontuação, passa a tratar do tema pelas funções da pontuação, no qual, segundo o autor, concerne na indicação de pausas e inflexões da voz, separações silábicas, expressões e orações que devem ser destacadas e de dar sentido à frase.

De acordo com o emprego sintático da vírgula, alguns gramáticos detalham o tema de forma bastante similar. Segundo Luft (1996), Cunha (2001), Bechara (2009), Sautchuk (2010), Martins (2010), as ocorrências cujos 
elementos da oração se encontram na ordem direta ou quando há determinado elemento inserido nesta ordem, de modo a interromper a sequência das ideias, tais elementos devem ser isolados pela vírgula.

Segundo Cunha (2001), os termos essenciais e integrantes da oração estão atrelados uns com os outros sem pausa, portanto, não podem ser separados por vírgulas. Nesse viés, o uso da vírgula não é aceito entre a oração subordinada substantiva e a sua oração principal. Com base na regra geral sobre o uso da vírgula entre o sujeito e o verbo, Luft (1996, p. 23) afirma que não é permitido o uso da vírgula entre ambos os elementos, contudo, caso haja explicativos, vocativos e intercalações, para marcar esses encaixes, deve utilizar duas vírgulas, isolando-os. Sautchuk (2010) aborda que essa proibição ocorre porque a ordem sujeito, verbo e complemento não é delimitada melodicamente pela vírgula de modo a explicar o mesmo fenômeno e Hauy (2014), afirma que tais elementos estão atrelados pela dependência sintática e, devido a essa dependência, não se separam por vírgulas.

Inicialmente, percebe-se que a divisão realizada pelos autores para explicar o emprego da vírgula no que tange ao período simples e o período composto parece ser meramente didática, uma vez que, ao explicitar que não se separa o sujeito do verbo e de seus complementos, compreende-se que há orações que desempenham estas funções no interior dos enunciados. Ou seja, sua separação umas das outras não deve ocorrer; ou quando se tem a assertiva que palavras e expressões explicativas também são isoladas por vírgulas, as orações que possuem essa função estão incluídas.

\section{O USO OU O NÃO USO DA VÍRGULA NA ESCRITA DE TEXTOS ACADÊMICOS}

Para a efetiva análise, como forma de constatar sobre o uso ou o não uso da vírgula na escrita de textos acadêmicos, foram selecionadas para composição do corpus cinco produções escritas da disciplina Trabalho Final de Leitura e Produção de Textos dos alunos do curso de Geografia da Universidade Federal do Triângulo Mineiro (UFTM).Por se tratar de uma pesquisa qualitativa, não será o dado repetido que terá relevância, mas o dado que, na relação com outros, 
embora aparentemente isolado, permita a construção de uma compreensão acerca de como o aluno emprega à vírgula na produção da escrita. Os textos que compõem o corpus são identificados pela letra T de "texto" e números que indicarão se aluno 01 ou 02 e, assim, sucessivamente; ou, seja, nesse sentido, a preocupação maior é com a não identificação dos autores das produções textuais.

No que tange ao uso recorrente da vírgula, percebe-se que o autor do texto 1 faz uso recorrente da pontuação, como se fora uma pausa de pequena durabilidade, tal como assevera Martins (2010), no entanto, a recorrência causa estranhamento.

Petróleo brasileiro S.A ou mais conhecida como Petrobras,
uma estatal, no ramo da extração petrolífera no Brasil,
fundada no ano de 1953 sob o então governo de Getúlio
Vargas, em meios a leis polêmicas que dividem opiniões sobre
o domínio do petróleo brasileiro e também campanhas que
visavam garantir que a exploração do petróleo em território
brasileiro não fosse entregue a empresas do exterior, assim
então nascia a Petrobras uma das maiores estatais no ramo
da extração de petróleo do mundo. [T. 1]

Inicialmente, o autor recorre à vírgula quanto ao seu uso sintático a fim de marcar o aposto "uma estatal", ou seja, mediante ao uso da vírgula especificase o substantivo "Petrobras". No entanto, até o final do fragmento, a vírgula é usada como única pontuação, como por exemplo, em detrimento do ponto seguido: "fundada no ano de 1953 sob o então governo de Getúlio Vargas, em meios a leis polêmicas que dividem opiniões sobre o domínio do petróleo brasileiro [...]". Além disso, observa-se a vírgula sendo utilizada no lugar do ponto final, uma vez que o autor inicia a oração com uma conjunção conclusiva "Assim".

Segundo a concepção de Rocha Lima (2008), têm-se as pontuações atreladas pelas pausas rítmicas, sendo as que interrompem o discurso e a pausa que indica a finalização do discurso. No entanto, verifica-se que o estudante 01 faz uso da vírgula em detrimento do ponto final, "isso a disputa por ele é cada vez maior, estudiosos preveem a escassez do petróleo em meados de 2067". 
Ou seja, não há a quebra discursiva e o início de uma nova oração, mas sim, ambas orações coordenadas sendo interligadas por vírgulas.

Vale a pena lembrar que o petróleo é um minério de fonte não
renovável, por isso a disputa por ele é cada vez maior, estudiosos
preveem a escassez do petróleo em meados de 2067, e então o
Brasil terá entregado toda sua riqueza mineral do petróleo à ...[T.
1]

De acordo com Luft (1996), o uso da pontuação está atrelado aos aspectos sintáticos e não prosódicos, no entanto, verifica-se o uso da vírgula também como quebra rítmica.

A impressão que se tem é que o Brasil é uma casa mal administrada, que ao final do mês fecha as contas no vermelho e se vende um móvel, para saldar uma conta a ser paga, mas a pergunta que fica...[T.1]

O petróleo é um recurso energético natural, o que entendemos como petróleo é uma mistura química menos densa que a água. $[\mathrm{T} .3]$

Alinhada na mesma concepção do uso da vírgula em relação ao modo sintático e não prosódico, Mesquita (1996), por sua vez, atrela o uso diante de vocativos, apostos, elipses, etc. Porém, nos exemplos abaixo, verifica-se que o uso da vírgula não fora empregado, uma vez que o estudante se refere ao aposto.

Segundo a matéria da BBC NEWS a especialista em gestão de petróleo Tina Hunter afirma que existem três modelos de exploração de petróleo no mundo. [T.4]

De acordo com Tina Hunter especialista em gestão de petróleo o monopólio de grandes empresas sobre um determinado produto ou setor, ou seja, o controle absoluto sobre os mesmos resulta na corrupção. [T.4]

Entretanto as polêmicas que envolvem a Petrobras ainda são muito recorrentes no cotidiano do país...[T.1] 
Entretanto a Petrobras possui o papel de estimular os projetos que, ajustados ao cenário de preços mais baixos do combustível, atendam aos interesses do País...[T.4]

Então para não parecer extremamente radical vejo que a Petrobras gera empregos e alimenta muitas famílias...[T.4]

Em relação ao não uso da vírgula, a predominância concerne diante das conjunções, ou seja, os estudantes tendem a não usá-la. Porém, a depender da posição da conjunção em determinado período composto, ou seja, aquele formado por duas orações, o emprego da vírgula será obrigatório (quando se estiver diante de uma conjunção inicial) ou facultativo (quando o período tiver uma conjunção intermediária que não altera a ordem lógica). Estas atribuições do emprego da vírgula estão atreladas ao sentido da mensagem, uma vez que Ihe é conferida o papel para demarcar as próprias funções sintáticas dos elementos distribuídos aleatoriamente no interior das orações, cujo uso errôneo pode comprometer, sobretudo alterar o significado. No entanto, verificou-se que diante de um manancial de conceitos sobre o uso gramatical da vírgula qual, de fato, é o utilizado no ensino-aprendizagem, uma vez que embora o ensino da gramática seja ministrado, advém a dificuldade do emprego na produção escrita. Com base no que fora exposto, a gramática tradicional baseia seu uso no aspecto melódico, ou seja, na entonação e, sobretudo na pausa respiratória como direcionamento do uso da vírgula

\section{CONCLUSÃO}

Mediante ao levantamento de dados a respeito da vírgula e as análises textuais dos estudantes do curso de Geografia, evidencia-se que a vírgula é a parte fundamental da escrita, uma vez que seu uso está intrinsecamente relacionado com a estrutura da língua, seja no âmbito da sintaxe ou semântico. Além disso, tanto no interior das orações como no interior dos períodos compostos por coordenação ou subordinação, têm-se a indicação de pausas, de modo a separar e isolar acessórios que denotam determinado rompimento nas relações sintáticas, marcando uma quebra na ordem direta ou indicando a 
inserção de elementos no interior das orações. Nesse sentido, têm-se o uso errôneo da vírgula na produção escrita, de modo que o sujeito tende a usar a vírgula com base na respiração (na pausa), não respeitando os termos sintáticos e semânticos da língua portuguesa que, muitas vezes, não lhe é ensinado para essa finalidade, ou seja, saber e compreender como usar a pontuação. Assim sendo, verifica-se o embate para com a escrita que Barzotto (2016) retrata, porém, tal associado ao uso da vírgula, cujo medo ou incertezas sobre seu uso faz com que o sujeito, enquanto produtor de sua escrita, utilize a vírgula sem ir de encontro com os preceitos sintáticos e semânticos da língua.

\section{REFERÊNCIAS}

ABAURRE, Maria Luiza M., Português: Língua, Literatura, Produção de Textos. Volumes 1, 2 e 3: Maria Luiza M. Abaurre, Maria Bernadete M. Abaurre, Marcela Pontara São Paulo: Ed. Moderna Plus, 2010.

BARZOTTO, Valdir Heitor. Leitura, escrita e relação com o conhecimento. Campinas, SP: Mercado de Letras, 2016.

BECHARA, Evanildo, Moderna Gramática Portuguesa. Ed. Rio de Janeiro: Nova Fronteira, 2009.

CEGALA, Domingos Paschoal. Novíssima gramática da língua portuguesa. São Paulo: 48. Ed. São Paulo: Companhia Editora Nacional, 2008.

CUNHA, Celso; CINTRA, Luís F. Lindley Nova Gramática do português contemporâneo. 3 ed. Rio de Janeiro: Nova fronteira, 2001.

GERALDI, J. W. Portos de passagem. 2. ed. São Paulo: Martins Fontes, 1993.

GERALDI, J. W. Linguagem e Trabalho Linguístico. 4. Ed. São Paulo: Martins Fontes, 2003.

HAUY, Amini Boainain. Gramática da Língua Portuguesa Padrão: Com Comentários e Exemplários Redigida Conforme o Novo Acordo Ortográfico / Amini Bouainain Hauy. São Paulo, Editora da Universidade de São Paulo, 2014.

LUFT, Celso Pedro. A vírgula. 2 Ed. São Paulo: Ática, 1996.

MARTINS, Dileta Silveira. Português instrumental: de acordo com as normas da ABNT. 29. Ed. São Paulo: Atlas, 2010. 
MESQUITA, Roberto Melo. Gramática da Língua Portuguesa. 8 ed. São Paulo: Saraiva, 1996.

ROCHA LIMA, Carlos Henrique da. Gramática normativa da língua portuguesa. 47. Ed. Rio de Janeiro: José Olympio, 2008.

SAUSSURE, Ferdinand de. Curso de Linguística Geral. São Paulo: Editora Cultrix, 2008.

SAUTCHUK, Inez. Prática de Morfossintaxe: como e por que aprender análise (morfo) sintática. 2. Ed. Barueri: Manole, 2010.

TERRA, Ernani. Curso prático de gramática. Ed. rev. e ampl. São Paulo: Scipione, 1996. 